
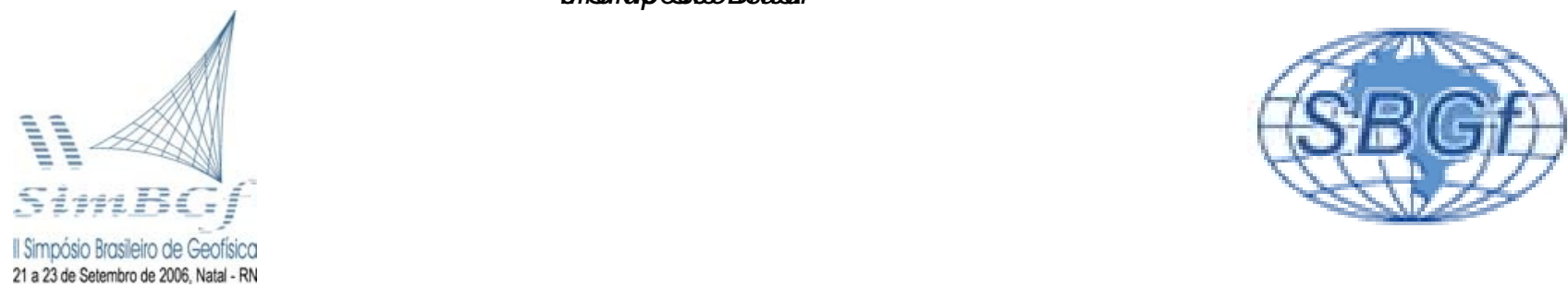

\title{
Localização de interferências no sitio controlado de geofísica rasa do IAG-USP através do método eletromagnético indutivo
}

\author{
*Vinícius Rafael Neris dos Santos ${ }^{1}$ \& Jorge Luís Porsani ${ }^{1}$ \\ ${ }^{1}$ Departamento de Geofísica (IAG-USP) - Emails: vinicius@iag.usp.br \& porsani@iag.usp.br
}

Copyright 2006, SBGf-Sociedade Brasileira de Geofísica

Este texto foi preparado para a apresentação no Il Simpósio de Geofísica da

Sociedade Brasileira de Geofísica, Natal, 21-23 de setembro de 2006. Seu conteúdo

foi revisado pela Comissão Tecno-científica do II SR-SBGf mas não necessariament

reprevis pela Comissão Tecno-cientifica do II SRSBGf mas náo necessariamente

ou parcial deste material para propósitos comerciais sem prévia autorização da SBGf

\section{Resumo}

A interpretação de dados de investigações geofísicas rasas pode ser complexa devido às incertezas a respeito dos alvos em subsuperfície. Para reduzir as ambigüidades e auxiliar a interpretação dos dados de superfície foi instalado no campus da USP em frente ao prédio do IAG - Instituto de Astronomia, Geofísica e Ciências Atmosféricas, o primeiro Sítio Controlado de Geofísica Rasa (SCGR) do Brasil. Diferentes alvos foram instalados em várias profundidades ao longo de 7 linhas. Os alvos instalados simulam os encontrados em estudos ambientais, arqueológicos, geotécnicos e de planejamento urbano. Neste trabalho são apresentados os resultados da aplicação do método eletromagnético indutivo (EM38) ao longo de uma faixa caracterizada por tubos de aço.

\section{Introdução e Objetivos}

O SCGR do IAG está situado na borda da Bacia Sedimentar de São Paulo (Figura 1). A área é composta por um aterro argilo-siltoso seguido de uma camada de argilas com matéria orgânica até $6 \mathrm{~m}$. A partir daí predominam sedimentos areno-argilosos das formações Resende e São Paulo sobrepostos ao embasamento granito-gnáissico. Dados de três poços para pesquisas geológicas-geofísicas, perfurados na área de estudos, mostram que a espessura dos sedimentos não ultrapassa 53 metros (Porsani et al., 2004). O SCGR tem dimensões de $50 \mathrm{~m} \times 30 \mathrm{~m}$, sendo composto por 7 linhas de $30 \mathrm{~m}$ cada, dispostas ao longo da direção $\mathrm{N}-\mathrm{S}$ magnético e um cano metálico de $4 \mathrm{~cm}$ de diâmetro externo foi instalado na posição de 15 metros ao longo da direção $E-W$, servindo como alvo-guia que cruza todas as linhas instaladas no SCGR. Cada uma das 7 linhas é caracterizada com um tipo específico de material. Os alvos foram escolhidos para terem respostas magnéticas, condutivas ou para gerarem reflexões nos perfis de GPR.
Com a instalação do SCGR foi dado um importante passo para melhorar o conhecimento relativo às respostas geofísicas de alvos rasos como os encontrados nos estudos ambientais, de arqueologia, de engenharia e de planejamento urbano. Os métodos geofísicos são muito utilizados para identificar objetos enterrados, sendo os principais o eletromagnético indutivo, o GPR e a eletrorresistividade.

Nesta pesquisa foi utilizado o método eletromagnético indutivo (EM38) visando caracterizar tubulações metálicas de 4" $(10,16 \mathrm{~cm})$ de diâmetro instaladas no SCGR do IAG/USP, na qual simulam a passagem de água e de gás nos grandes centros urbanos.

O método eletromagnético indutivo diferencia-se de outras tecnologias pelo uso de equipamentos de operação simples, rápida e de baixo custo. Entre 1919 e 1922 , os suecos $H$. Lundberg e K. Sundberg começaram a trabalhar com exploração elétrica com campos variáveis e principalmente na observação da intensidade do campo magnético, surgindo assim o método eletromagnético indutivo. $O$ uso da propagação de campos eletromagnéticos de baixa freqüência usada atualmente foi desenvolvida entre 1925 e 1940 por Sundberg e H. Hedström, a tecnologia de emissor e receptor móveis foram apresentados entre 1940 e 1950.

\section{Metodologia e Aquisição dos Dados}

A propagação da energia eletromagnética é descrita pelas Equações de Maxwell através dos campos elétricos e campos magnéticos. Uma vez conhecidas suas propriedades elétricas e magnéticas, com as equações podemos abranger o comportamento da propagação e da atenuação do campo eletromagnético em um meio. $O$ princípio do método eletromagnético indutivo é medir diretamente a condutividade elétrica, propriedade física inversamente proporcional à resistividade elétrica, dos materiais em subsuperfície através dos campos elétricos e magnéticos descritos pelas equações de Maxwell.

O equipamento EM38 (Geonics Ltd), conhecido como condutivímetro de solo portátil, possui o espaçamento entre as bobinas de 1 metro e freqüência de operação de $14,6 \mathrm{kHz}$. Ele possibilita obter a condutividade elétrica e a susceptibilidade magnética do meio nas profundidades teóricas de 0,75 m (DMH - dipolo magnético horizontal) e 
1,5 m (DMV - dipolo magnético vertical) (Figura 2). Suas principais aplicações são: estudos de agricultura de precisão, mapeamento e salinidade do solo, arqueologia e mapeamento de tubulações metálicas.

Quando uma bobina transmissora energizada com uma corrente alternada é colocada em um meio uniforme e uma bobina transmissora está localizada em uma distância curta, o campo magnético variante no tempo proveniente da corrente alternada da bobina transmissora induz fracas correntes no solo. Estas correntes geram um campo magnético secundário $\left(\mathrm{H}_{\mathrm{s}}\right)$ que é sentido junto com o campo magnético primário $\left(H_{p}\right)$ pela bobina receptora. A razão do espaçamento entre as bobinas dividido pelo skin depth $(\delta)$ é conhecido como o "número de indução" $(B)$. Quando o número de indução é muito menor do que 1 , então a razão do $\mathrm{H}_{\mathrm{s}}$ com o $\mathrm{H}_{\mathrm{p}}$ no receptor é diretamente proporcional a condutividade aparente $\left(\sigma_{\mathrm{a}}\right)$.

$$
\frac{\mathrm{H}_{\mathrm{s}}}{\mathrm{H}_{\mathrm{p}}} \approx \frac{\mathrm{i} \omega \mu_{0} \sigma \mathrm{s}^{2}}{4}
$$

sendo, $i=\sqrt{-1}, \omega=2 \pi \mathrm{f}, \mathrm{f}$ a freqüência em $\mathrm{Hz}, \mu_{0} \mathrm{a}$ permeabilidade magnética no vácuo, $\sigma$ a condutividade, e $s$ a separação entre as bobinas em metros (McNeill, 1980).

Para a aquisição dos dados a área do SCGR foi delimitada com trenas e foram feitas marcações com bandeirinhas a cada 1 metro. Os perfis EM38 foram adquiridos por faixas de 4 metros de largura, totalizando um perfil a cada 0,5 metro, sendo as medidas feitas também a cada 0,5 metro (Figura 3). Os perfis foram adquiridos no sentido $\mathrm{S}-\mathrm{N}$ e ao término da aquisição de cada faixa de dados uma linha base era reocupada para corrigir os dados quanto à variação de temperatura. Os perfis foram adquiridos no modo $\mathrm{DMH}$ e no modo DMV. Os dados foram tratados através do software Excel e os mapas de condutividade elétrica aparente foram obtidos com o software Surfer.

\section{Discussão dos Resultados}

A faixa de estudos corresponde à linha do SCGR onde estão instaladas as tubulações metálicas com 4" $(10,16$ $\mathrm{cm}$ ) de diâmetro, dispostas na horizontal (direções EW e NS magnético), vertical e inclinada. Essas tubulações simulam o transporte de água, gás e alvos geológicos magnéticos, por exemplo, mineralizações e diques. A Figura 4a mostra a disposição das tubulações metálicas instaladas na linha 6 do SCGR e as Figuras 4b e 4c mostram os resultados obtidos com 0 método eletromagnético indutivo - EM38 nos modos DMH $(0,75 \mathrm{~m})$ e DMV $(1,5 \mathrm{~m})$, respectivamente.

Os resultados mostraram seis anomalias de condutividade correspondentes às posições de 1-4, 5-7, $15,20,23$ e 29 metros. As baixas condutividades observadas nas posições 1-4, 20 e 23 metros coincidem com as posições dos tubos metálicos dispostos na horizontal nas direções EW e NS magnético. Os baixos valores tendendo a condutividade negativa são semelhantes à do cano metálico-guia localizado na posição de 15 metros. Os baixos valores de condutividade não refletem a propriedade física do meio, e sim uma resposta devido ao elevado campo magnético secundário gerado por objetos metálicos muito próximos às bobinas do equipamento (McNeill, 1980). Todas as anomalias verificadas no perfil coincidem com as posições dos tubos metálicos, e as anomalias de maiores amplitudes ocorrem sobre alvos rasos, ou seja, aqueles enterrados a profundidades inferiores a 1 metro. De acordo com os mapas, as anomalias alongadas correspondem aos tubos metálicos dispostos na horizontal (EW ou NS) e a anomalia circular (5) corresponde ao tubo metálico disposto na vertical.

\section{Conclusões}

O método eletromagnético indutivo (EM38) mostrou-se satisfatório na localização dos alvos metálicos até dois metros de profundidade, apresentando praticidade e rapidez na aquisição dos dados. Por outro lado, alguns alvos metálicos não foram detectados devido estarem além da profundidade de investigação inerente ao método, bem como pelo pequeno volume de metal. O método é considerado adequado para localizar alvos metálicos e tem sido bastante difundido em estudos arqueológicos na localização de paleofogueiras e em estudos de agricultura de precisão no mapeamento da condutividade elétrica do solo.

\section{Agradecimentos}

À PETROBRAS/CENPES pela bolsa de Pesquisa de Iniciação Científica. Ao IAG/USP pelo apoio e infraestrutura para a realização desta pesquisa. Aos colegas Welitom, Ernande, Robson e Cláudia pelos apoios recebidos durante a aquisição e o tratamento dos dados.

\section{Referências}

Borges, W.R. \& Porsani, J.L., 2003. Caracterização geofísica rasa do sítio controlado do IAG-USP: resultados preliminares. $8^{\circ}$ Inter. Congr. SBGf, Rio de Janeiro/RJ.

McNeill, J.D., 1980. Electromagnetics terrain conductivity measurement at low induction numbers. Tech. Note TN-6, Geonics Ltd, Mississauga, Ont., Canadá, 13p.

Porsani, J.L.; Borges, W.R.; Elis, V.R.; Diogo, L.A.; Hiodo, F.Y.; Marrano, A.; Birelli, C.A., 2004. Investigações geofísicas de superfície e de poço no sítio controlado de geofísica rasa do IAG/USP. Revista Brasileira de Geofísica, Rio de Janeiro, v.22, n.3, p.245-258.

Porsani, J.L.; Borges, W.R.; Rodrigues, S.I.; Hiodo, F.Y., 2006. O sítio controlado de geofísica rasa do IAG/USP: Instalação e resultados GPR 2D-3D. Revista Brasileira de Geofísica, Rio de Janeiro [No Prelo]. 


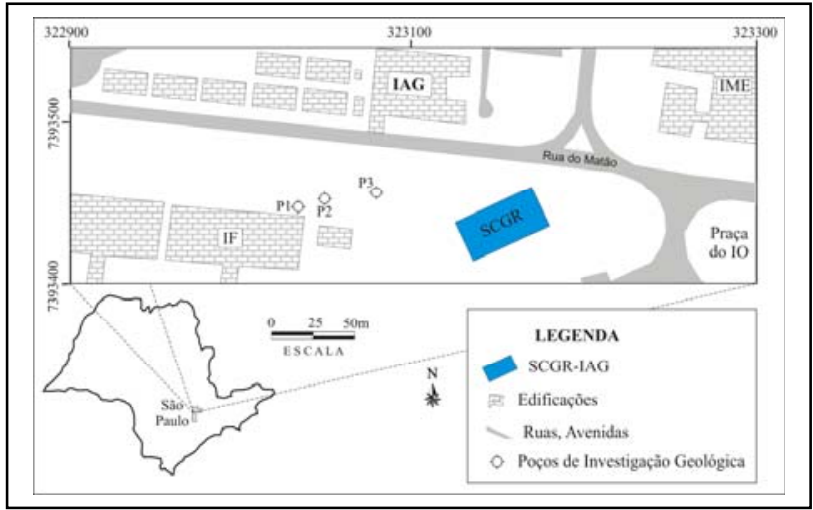

Figura 1 - Localização do SCGR do IAG/USP (Porsani et al., 2006).

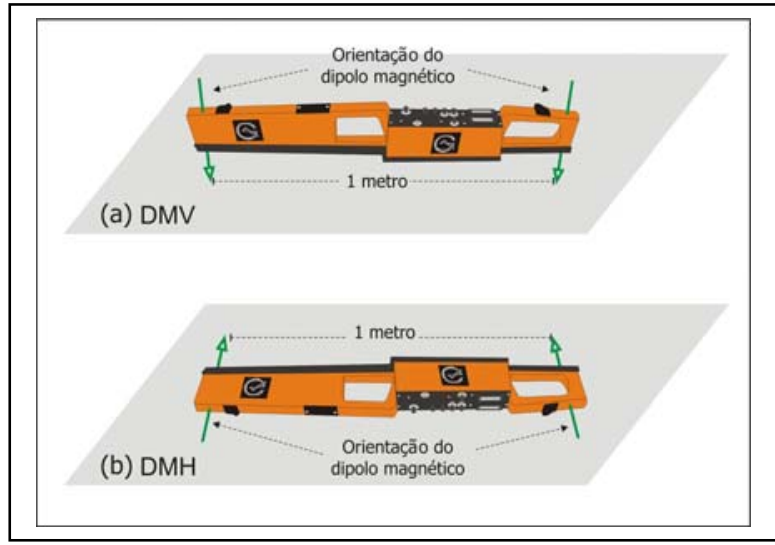

Figura 2 - Modos de aquisição de dados com o EM38. a) DMV, b) DMH (Borges \& Porsani, 2003).

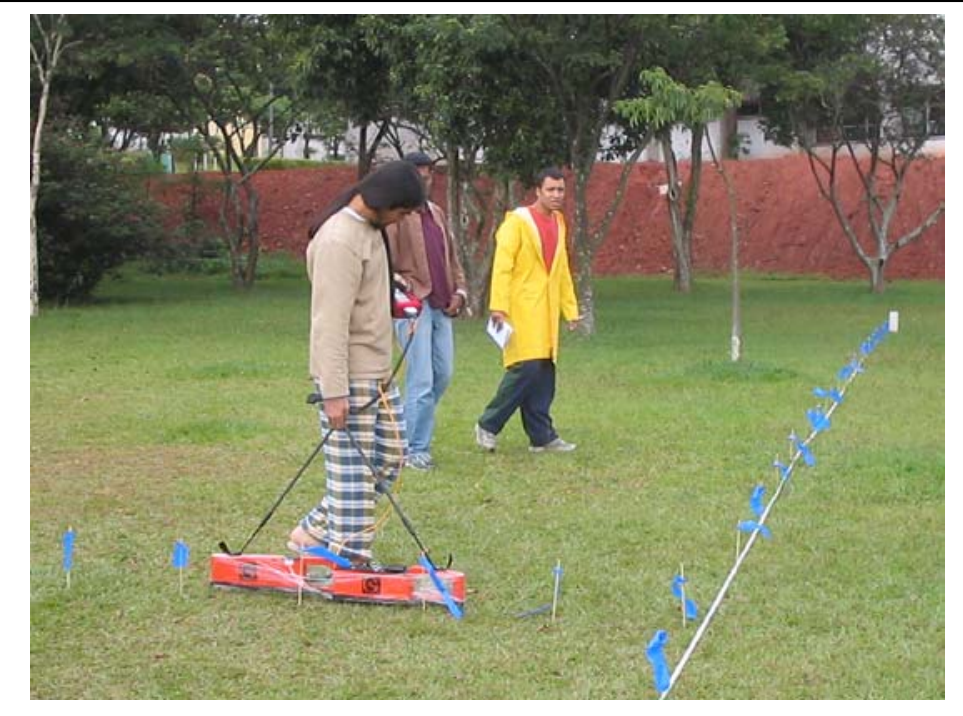

Figura 3. Aquisição dos dados no modo DMV. 


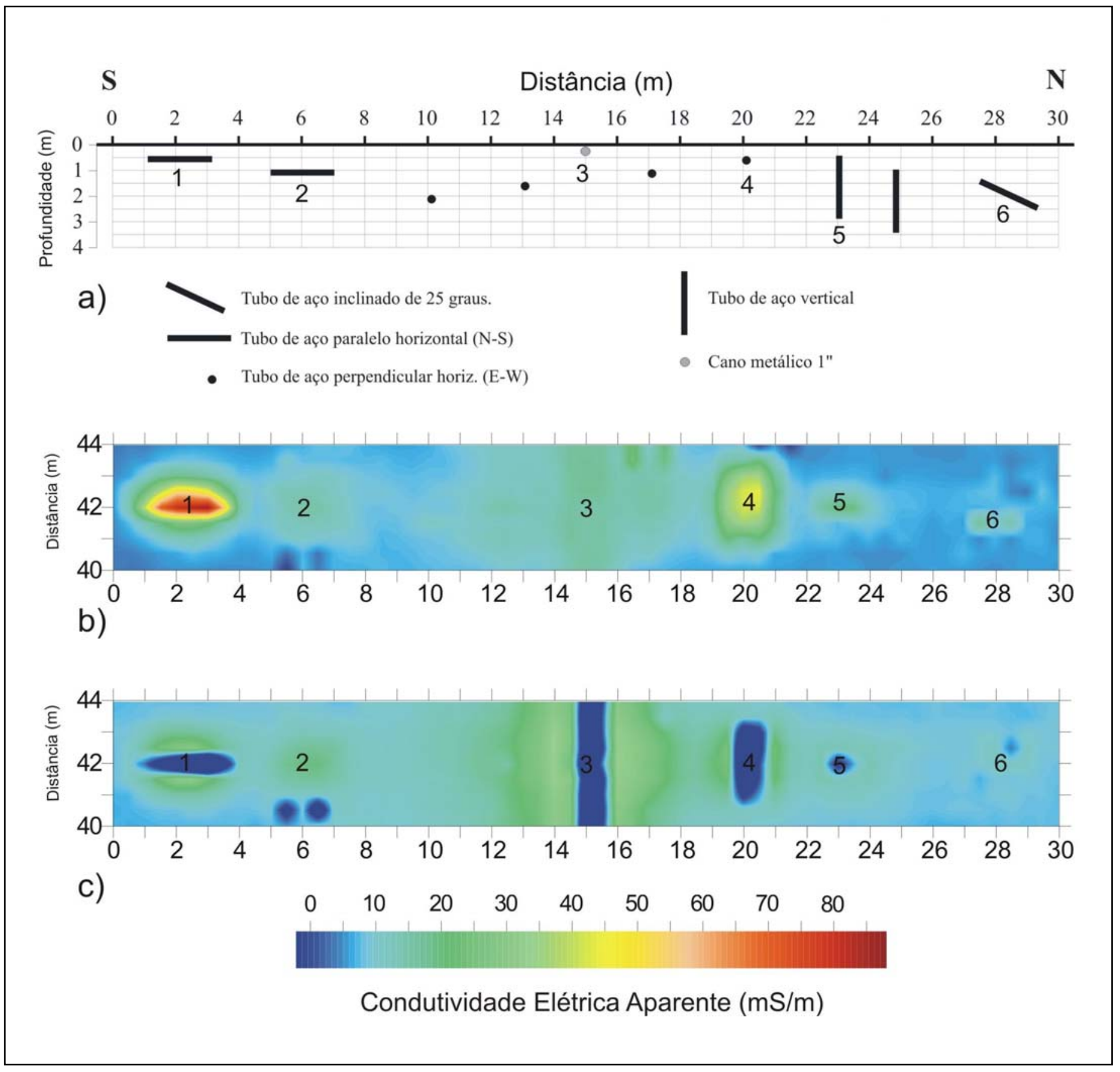

Figura 4 - a) disposição dos canos metálicos instalados na linha 6 do SCGR, b) resultados obtidos com o modo DMH e c) resultados obtidos com modo DMV. 